\title{
Consumo de forragem e desempenho animal em cultivares de Urochloa humidicola sob lotação contínua
}

\author{
Clovis David Medeiros Martins ${ }^{(1)}$, Valéria Pacheco Batista Euclides ${ }^{(2)}$, Rodrigo Amorim Barbosa(2), \\ Denise Baptaglin Montagner ${ }^{(2)}$ e Tiago Miqueloto ${ }^{(3)}$
}

\begin{abstract}
(1)Universidade Federal de Mato Grosso do Sul, Caixa Postal 549, CEP 79070-900 Campo Grande, MS. E-mail: clovisagro@gmail.com (2)Embrapa Gado de Corte, Caixa Postal 154, CEP 79002-970 Campo Grande, MS. E-mail: valeria.pacheco@embrapa.br, rodrigo.barbosa@embrapa.br, denise.montagner@embrapa.br ${ }^{(3)}$ Universidade do Estado de Santa Catarina, Caixa Postal 138, CEP 88032-000 Lages, SC. E-mail: tiagomiqueloto@gmail.com
\end{abstract}

Resumo - O objetivo deste trabalho foi avaliar o acúmulo de forragem, a estrutura do dossel, o valor nutritivo, o consumo de forragem e a produção animal, em pastos de Urochloa humidicola sob lotação contínua. As cultivares BRS Tupi e Comum foram avaliadas durante os períodos de seca e das águas (julho de 2011 a agosto de 2012), em delineamento experimental de blocos ao acaso, com dois tratamentos e seis repetições. Mensalmente, os animais foram pesados e os pastos amostrados para a determinação de: taxa de acúmulo de forragem (TAF); massa de forragem; percentagens de folha (PF), colmo e material morto (PM); e valor nutritivo. O consumo de matéria seca (CMS) foi determinado uma vez a cada período. 'BRS Tupi' apresentou maiores TAF e PF e menor PM do que a 'Comum', durante o período das águas. O valor nutritivo, o CMS e o ganho médio diário foram semelhantes entre as duas cultivares. O conteúdo de proteína bruta da forragem - 6,0 e 5,0\%, respectivamente, para os períodos das águas e seco - foi o principal fator limitante ao CMS. 'BRS Tupi' recebeu maior taxa de lotação e, consequentemente, possibilitou maior ganho de peso vivo por área (192 $\mathrm{kg} \mathrm{ha}^{-1}$ por ano) do que a 'Comum' (126 kg ha-1 por ano). A 'BRS Tupi' é uma boa alternativa para a diversificação de pastagens em solos de baixa fertilidade sujeitos a alagamento temporário.

Termos de indexação: Brachiaria humidicola, Urochloa humidicola, BRS Tupi, estrutura do dossel, quicuio-da-Amazônia, taxa de lotação.

\section{Forage intake and animal performance in Urochloa humidicola cultivars under continuous stocking}

\begin{abstract}
The objective of this work was to evaluate forage accumulation, canopy structure, nutritive value, forage intake, and animal production in pastures of Urochloa humidicola under continuous stocking. The cultivars BRS Tupi and Comum were evaluated during the drought and wet periods (July 2011 to August 2012), in a randomized complete block experimental design, with two treatments and six replicates. Monthly, the animals were weighted and the pastures sampled for the determination of: forage accumulation rate (FAR); forage mass; percentages of leaves (PL), culms, and dead material (DL); and nutritive value. Forage intake (FI) was determined once a period. 'BRS Tupi' had a higher FAR, PL, and DL than 'Comum', during the wet period. The nutritive value, FI and the daily weight gain were similar between both cultivars. Forage protein content -6.0 and $5.0 \%$, for the wet and drought periods, respectively - was the main limiting factor for FI. 'BRS Tupi' had higher stocking rates and, consequently, made possible a higher live weight gain per area $\left(192 \mathrm{~kg} \mathrm{ha}^{-1}\right.$ per year) than 'Comum' (126 kg ha-1 per year). 'BRS Tupi' is a good alternative for diversification of pastures in soils with low fertility that are temporarily subjected to flooding.
\end{abstract}

Index terms: Brachiaria humidicola, Urochloa humidicola, BRS Tupi, canopy structure, creeping signalgrass, stocking rate.

\section{Introdução}

A braquiária humidícola, ou quicuio-da-Amazônia - Urochloa humidicola (Rendle) Morrone \& Zuloaga [Syn. Brachiaria humidicola (Rendle) Schweick] -, é uma espécie forrageira de hábito decumbente, enraizamento rápido e crescimento vigoroso. A espécie tem apresentado grande expansão no trópico úmido sul-americano, em decorrência de sua alta capacidade de adaptação a solos ácidos e de baixa fertilidade natural. Além disso, essa forrageira tolera solos alagados, bem como períodos de seca (Valle et al., 2010). 
No mercado nacional, encontram-se disponíveis três cultivares de $U$. humidicola: a Llanero; a Comum (Cook et al., 2005); e a BRS Tupi (Unipasto, 2013). A cultivar BRS Tupi apresenta florescimento precoce (primavera/verão) e produtividade semelhante à Comum, de aproximadamente $400 \mathrm{~kg} \mathrm{ha}^{-1}$ de sementes puras. Seus estolões são mais longos e mais densos do que os de outras cultivares, o que lhe confere melhor capacidade de controle de plantas invasoras (Unipasto, 2013). Segundo Lascano \& Euclides (1996), a cultivar Comum apresenta baixo valor nutritivo. No entanto, pouco se sabe sobre o valor nutritivo da BRS Tupi sob pastejo, em razão de seu recente lançamento. Essa característica, geralmente, tem grande influência sobre o consumo de forragem e, consequentemente, sobre o desempenho animal (Mott \& Moore, 1970).

Em regime de pastejo, o consumo da forragem é função de processos que ocorrem na interface entre animal e ambiente pastoril (Pittroff \& Soca, 2006). Os fatores que afetam o consumo de matéria seca, por animais em pastejo, podem ser classificados em nutricionais e não nutricionais. Vários autores ressaltaram que o consumo de forragem é influenciado e limitado pela estrutura do dossel e pelo valor nutritivo (Palhano et al., 2007; Trindade et al., 2007; Carvalho et al., 2008; Difante et al., 2009). A cultivar BRS Tupi apresenta características estruturais que favorecem o pastejo e que, portanto, podem resultar em melhor desempenho animal (Unipasto, 2013).

O objetivo deste trabalho foi avaliar a estrutura do dossel, o valor nutritivo, o consumo de forragem e a produção animal, em pastagens das cultivares de U. humidicola, BRS Tupi e Comum, sob lotação continua.

\section{Material e Métodos}

O experimento foi realizado na Embrapa Gado de Corte, em Campo Grande, MS (20 $27^{\circ} \mathrm{S}, 54^{\circ} 37^{\prime} \mathrm{W}$, a $530 \mathrm{~m}$ ), de junho de 2011 a agosto de 2012. O solo da área experimental é classificado como Latossolo Amarelo ácrico típico, moderadamente drenado (Santos et al., 2006). Portanto, o solo apresenta problemas de drenagem. As análises de solo da área experimental, realizadas na camada de $0-20 \mathrm{~cm}$, em julho de 2011, apresentaram os seguintes resultados: $\mathrm{pH}\left(\mathrm{CaCl}_{2}\right)$ 5,40; Ca, 1,31 $\mathrm{cmol}_{\mathrm{c}} \mathrm{dm}^{-3} ; \mathrm{Mg}, 0,94 \mathrm{cmol}_{\mathrm{c}} \mathrm{dm}^{-3} ; \mathrm{K}$,
0,13 $\mathrm{cmol}_{\mathrm{c}} \mathrm{dm}^{-3} ; \mathrm{Al}, 0,01 \mathrm{cmol}_{\mathrm{c}} \mathrm{dm}^{-3} ; \mathrm{T}, 6,17 \mathrm{cmol}_{\mathrm{c}}$ $\mathrm{dm}^{-3}$; V, 38,2\%; e P (Mehlich 1), 0,51 $\mathrm{mg} \mathrm{dm}^{-3}$.

O clima da região, segundo a classificação de Köppen, é do tipo tropical chuvoso de savana, subtipo Aw. Os dados climáticos obtidos durante o período experimental foram coletados na estação meteorológica da Embrapa Gado de Corte (Figura 1). Para cálculo do balanço hídrico mensal, foram utilizados os dados de temperatura média e precipitação mensal acumulada. A capacidade de armazenamento de água no solo (CAD) foi de 82,8 mm (Figura 2).

Os pastos foram estabelecidos em novembro de 2003 e utilizados sob pastejo desde essa época. Em 2003, $1,3 \mathrm{Mg}$ de calcário dolomítico $(\mathrm{PRNT}=75 \%) \mathrm{e}$ $400 \mathrm{~kg} \mathrm{ha}^{-1}$ da fórmula NPK 15-15-15 foram aplicados ao solo. Em novembro de 2010, 2011 e 2012, foram realizadas adubações de manutenção com $30 \mathrm{~kg} \mathrm{ha}^{-1} \mathrm{de}$ $\mathrm{P}_{2} \mathrm{O}_{5}$ e $30 \mathrm{~kg} \mathrm{ha}^{-1}$ de $\mathrm{K}_{2} \mathrm{O}$ e, em janeiro de cada ano, $50 \mathrm{~kg} \mathrm{ha}^{-1}$ de $\mathrm{N}$ na forma de ureia.

A área experimental, com nove hectares, foi dividida em 12 piquetes de 0,75 ha (seis piquetes para cada cultivar). O delineamento experimental em blocos ao acaso foi utilizado com dois tratamentos e seis repetições. Os tratamentos consistiram das cultivares BRS Tupi e Comum de U. humidicola. O método de pastejo utilizado foi o de lotação contínua com taxa de lotação variável.

Foram utilizados 40 bezerros da raça Nelore, com aproximadamente nove meses de idade e peso médio inicial de $180 \mathrm{~kg}$. Desses, foram selecionados 24 animais, que foram distribuídos nas unidades experimentais (dois por piquete), para que as médias de peso dos dois animais fossem praticamente a mesma para todos os piquetes. Esses animais permaneceram no mesmo piquete, como animais avaliadores, até o final do experimento. $\mathrm{O}$ restante do lote foi mantido em piquete reserva ( $6 \mathrm{ha}$ ) e utilizado nas unidades experimentais como animais reguladores, sempre que houvesse necessidade de ajuste da taxa de lotação, para manter os pastos à altura predeterminada de $20 \mathrm{~cm}$. Todos os animais receberam água e mistura mineral completa à vontade, além de manejo sanitário recomendado pela Embrapa Gado de Corte.

As alturas de dossel foram medidas semanalmente, com régua graduada em centímetros, em 30 pontos aleatórios por piquete. A altura de cada ponto correspondeu à altura média do dossel em torno da régua.

Pesq. agropec. bras., Brasília, v.48, n.10, p.1402-1409, out. 2013 DOI: $10.1590 / \mathrm{S} 0100-204 X 2013001000012$ 
A cada 28 dias, foram cortadas rente ao solo, em cada piquete, 15 amostras de $1 \mathrm{~m}^{2}$, distribuídas ao longo de três linhas. Essas amostras foram divididas em duas subamostras: uma foi pesada, seca em estufa de ventilação forçada de ar a $65^{\circ} \mathrm{C}$ até massa constante, e, então, novamente pesada; a outra foi separada

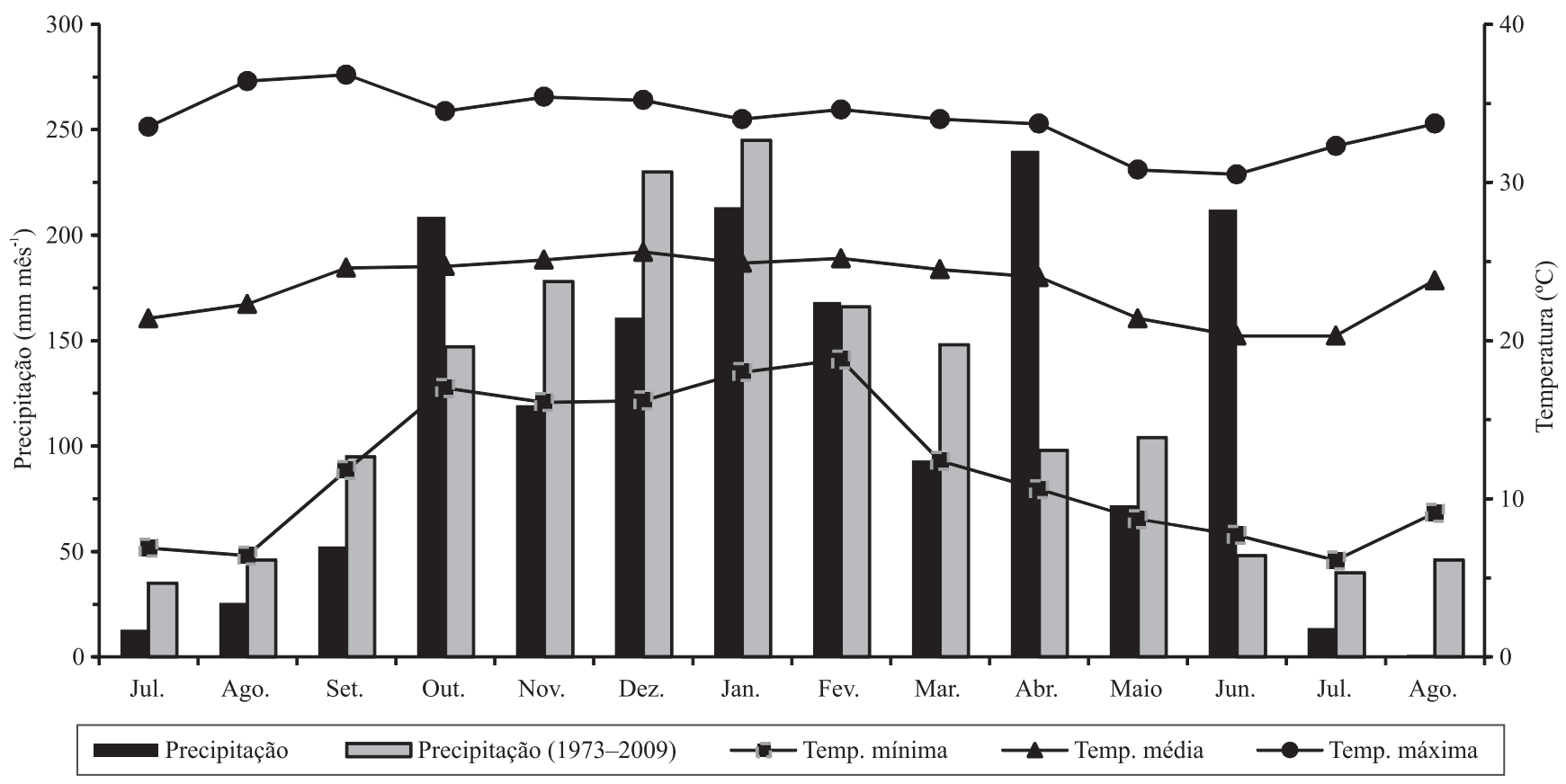

Figura 1. Precipitação pluvial mensal e média histórica (1973-2009) e temperaturas máxima, média e mínima mensal de julho de 2011 a agosto de 2012.

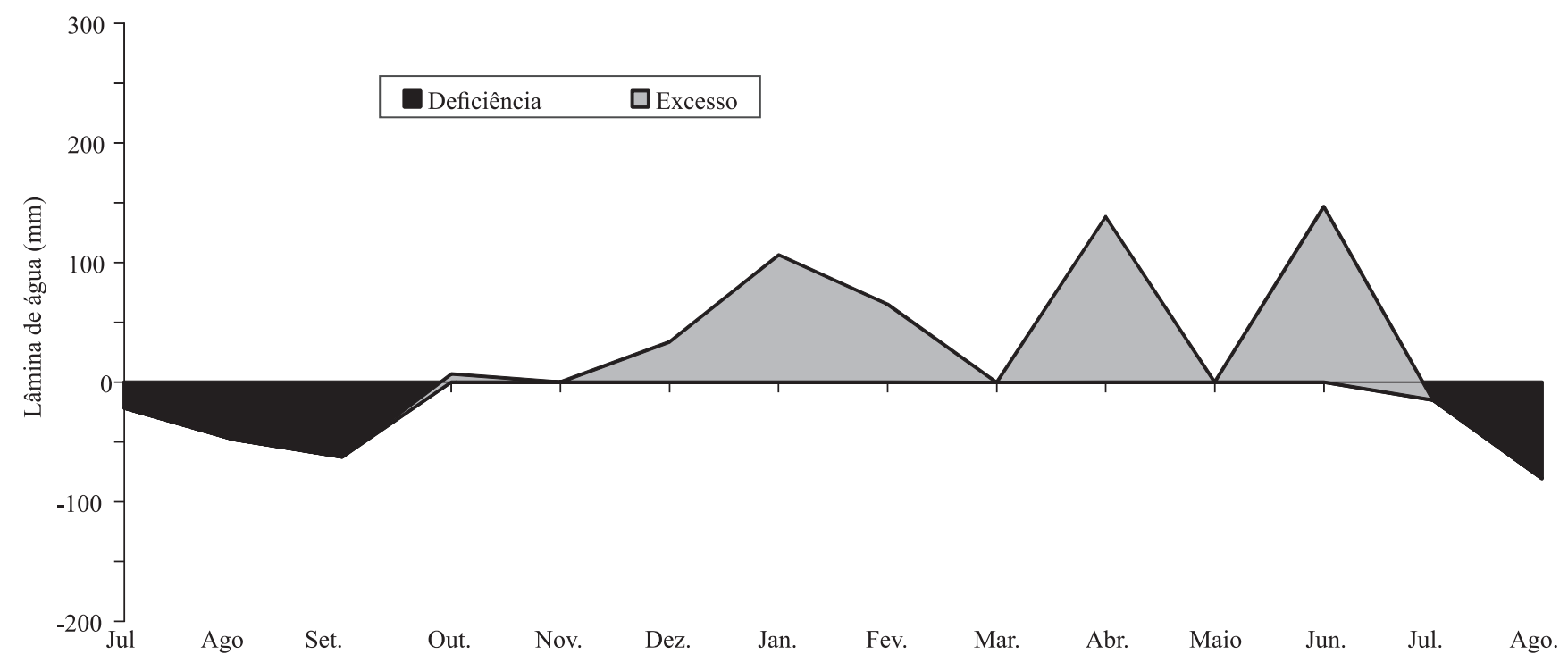

Figura 2. Balanço hídrico mensal, durante o período de julho de 2011 a agosto de 2012. 
em folha (lâmina foliar), colmo (colmo e bainha) e material morto. Estes componentes também foram secos em estufa, e a proporção de cada componente foi expressa em percentagem do peso total. De posse das proporções de cada componente na matéria seca, determinaram-se as relações folha:colmo (RFC) e folha: não folha (colmo + material morto; RFNF), bem como a massa de lâmina foliar.

A taxa de acúmulo de forragem foi determinada com uso de três gaiolas de exclusão $\left(1 \mathrm{~m}^{3}\right)$ por piquete. A cada 28 dias, as gaiolas foram alocadas em pontos representativos da altura média do pasto com massa e composição morfológica semelhantes às áreas em pastejo. A massa de forragem dentro e fora da gaiola foi obtida por cortes rentes ao solo. Após cada corte, as gaiolas foram realocadas no piquete, tendo-se seguido a mesma metodologia. A taxa de acúmulo de forragem foi obtida por meio da diferença entre as massas de forragem coletadas dentro (corte atual) e fora (corte anterior) das gaiolas, tendo-se considerado apenas a porção verde da planta (folha e colmo), dividida pelo número de dias entre as amostragens.

Amostras mensais foram coletadas para simular o pastejo dos animais. Essas amostras foram secas, moídas e analisadas para a determinação dos teores de proteína bruta, fibra em detergente neutro, lignina em detergente ácido, e digestibilidade in vitro da matéria orgânica, com uso do sistema de espectrofotometria de reflectância no infravermelho (NIRS).

Os animais avaliadores e reguladores foram pesados mensalmente, após jejum de 16 horas. O ganho de peso médio diário foi calculado pela diferença de peso dos animais avaliadores dividida pelo número de dias entre pesagens. A taxa de lotação foi calculada como o produto do peso médio dos animais avaliadores + reguladores, pelo número de dias em que eles permaneceram no piquete (Petersen \& Lucas Junior, 1968). O ganho de peso por área foi obtido pela multiplicação do ganho diário médio dos animais avaliadores pelo número de animais (avaliadores e reguladores) mantidos nos piquetes por mês.

O consumo de matéria seca foi estimado em setembro de 2011 (período seco) e em fevereiro de 2012 (período das águas). Utilizou-se óxido crômico como indicador externo, tendo-se aplicado $15 \mathrm{~g}$ de $\mathrm{Cr}_{2} \mathrm{O}_{3}$ por animal, por dia, durante sete dias. As coletas de fezes foram realizadas do $6^{\circ}$ ao $8^{\circ}$ dia. O fornecimento do indicador aos animais, o período de adaptação e a coleta de fezes seguiram a metodologia descrita por Valadares Filho et al. (2005). As fezes foram secas em estufa de ar forçado, a $50^{\circ} \mathrm{C}$, e analisadas para estimativa do teor de cromo, conforme Willians et al. (1962). A quantidade de fezes e a digestibilidade in vitro da matéria seca das amostras que simulavam o pastejo foram utilizadas para a estimativa do consumo de forragem.

Os dados foram agrupados em dois períodos: período seco (de junho a setembro de 2011 e de maio a agosto de 2012) e período das águas (de outubro de 2011 a abril de 2012). A análise estatística foi realizada por meio de um modelo matemático, com efeito aleatório de bloco e fixo de cultivar, período do ano e interações entre estes. Para todas as análises, utilizouse o procedimento mixed, do SAS Institute, versão 6.11 (SAS Institute, Cary, NC, EUA). A comparação de médias foi realizada pelo teste de Tukey, a 5\% de probabilidade.

\section{Resultados e Discussão}

A altura do dossel ficou próxima da meta preestabelecida de $20 \mathrm{~cm}$, exceto para a cultivar Tupi, durante o período da seca, que ficou bem abaixo da altura-meta, possivelmente em razão de um erro de manejo (Tabela 1).

Não se observou efeito do período do ano nem da interação entre gramínea e período do ano, para a massa de forragem (MF). Pastos da cultivar Comum apresentaram maior MF $\left(2.900 \pm 114,3 \mathrm{~kg} \mathrm{ha}^{-1}\right)$ do que os da BRS Tupi $\left(2.510 \pm 114,3 \mathrm{~kg} \mathrm{ha}^{-1}\right.$ de matéria seca). Observou-se interação entre os efeitos de cultivar e estação do ano, para todas as variáveis associadas a características dos pastos (Tabela 1), exceto para a relação folha: colmo (RFC). Não se observaram efeitos de cultivar e de período do ano para RFC, que apresentou média \pm erro-padrão de $2,7 \pm 0,3$.

Durante o período das águas, a taxa de acúmulo de forragem (TAF) foi maior para a cultivar BRS Tupi do que para a Comum; no entanto, no período seco, ela foi semelhante entre as cultivares (Tabela 1). Independentemente da cultivar, a TAF foi maior no período das águas do que no seco. O deficit hídrico e as baixas temperaturas observadas nessa época do ano são os responsáveis por esse resultado (Figuras 1 e 2). Comportamento semelhante foi relatado sobre as

Pesq. agropec. bras., Brasília, v.48, n.10, p.1402-1409, out. 2013 DOI: 10.1590/S0100-204X2013001000012 
cultivares de $U$. brizantha Marandu (Paula et al., 2012) e Xaraés (Pedreira et al., 2007).

Durante o período das águas, a cultivar Tupi apresentou maior percentagem de folhas (PF) e menor de material morto (PM), o que resultou em maior relação folha: não folha (RFNF) do que a Comum (Tabela 1). A percentagem de colmo (PC) foi semelhante entre as duas cultivares. Segundo Paula et al. (2012), em pastos de capim-marandu sob lotação contínua, a relação folha: não folha pode tornar-se um importante indicador da facilidade de preensão de forragem pelo animal, uma vez que a quantidade de matéria morta pode dificultar o acesso do animal a folhas verdes, o que restringiria o consumo de forragem. Vários autores ressaltam a importância da presença de colmo e material morto sobre a estrutura do dossel, a ingestão de forragem e o desempenho animal (Palhano et al.,

Tabela 1. Médias de cultivares de Urochloa humidicola quanto à altura do dossel, à taxa de acúmulo de forragem (TAF), às percentagens de folha, colmo e de material morto, à relação folha: não folha (RFNF), à digestibilidade in vitro da matéria orgânica (DIVMO) e ao consumo de matéria seca (CMS) pelos animais, em diferentes períodos do ano ${ }^{(1)}$.

\begin{tabular}{|c|c|c|c|c|}
\hline Período & 'BRS Tupi' & 'Comum' & Erro-padrão & p da interação \\
\hline & \multicolumn{4}{|c|}{ Altura $(\mathrm{cm})$} \\
\hline Águas & $22 \mathrm{aA}$ & $20 \mathrm{aA}$ & 1,0 & 0,0066 \\
\hline \multirow[t]{2}{*}{ Seca } & $14 \mathrm{bA}$ & $18 \mathrm{aA}$ & 1,0 & \\
\hline & \multicolumn{4}{|c|}{ TAF (kg ha ${ }^{-1}$ de MS por dia) } \\
\hline Águas & $23,8 \mathrm{aA}$ & $15,0 \mathrm{bA}$ & 1,6 & 0,0105 \\
\hline \multirow[t]{2}{*}{ Seca } & $7,0 \mathrm{aB}$ & $8,2 \mathrm{aB}$ & 2,2 & \\
\hline & \multicolumn{4}{|c|}{ Folha (\%) } \\
\hline Águas & $31,6 \mathrm{aA}$ & $23,4 \mathrm{bA}$ & 1,3 & 0,0022 \\
\hline \multirow[t]{2}{*}{ Seca } & $18,2 \mathrm{aB}$ & $18,2 \mathrm{aB}$ & 1,3 & \\
\hline & \multicolumn{4}{|c|}{ Colmo (\%) } \\
\hline Águas & $20,0 \mathrm{aA}$ & $16,3 \mathrm{aA}$ & 1,3 & 0,0309 \\
\hline \multirow[t]{2}{*}{ Seca } & $7,5 \mathrm{aB}$ & $9,5 \mathrm{aB}$ & 1,3 & \\
\hline & \multicolumn{4}{|c|}{ Material morto (\%) } \\
\hline Águas & $48,1 \mathrm{bB}$ & $60,2 \mathrm{aB}$ & 2,3 & 0,0028 \\
\hline \multirow[t]{2}{*}{ Seca } & $74,0 \mathrm{aA}$ & $72,3 \mathrm{aA}$ & 2,3 & \\
\hline & \multicolumn{4}{|c|}{ RFNF } \\
\hline Águas & $0,52 \mathrm{aA}$ & $0,34 \mathrm{bA}$ & 0,03 & 0,0034 \\
\hline \multirow[t]{2}{*}{ Seca } & $0,23 \mathrm{aB}$ & $0,22 \mathrm{aB}$ & 0,03 & \\
\hline & \multicolumn{4}{|c|}{ DIVMO (\%) } \\
\hline Águas & $55,2 \mathrm{aA}$ & $55,1 \mathrm{aA}$ & 0,5 & 0,0108 \\
\hline \multirow[t]{2}{*}{ Seca } & $47,0 \mathrm{aB}$ & $44,2 \mathrm{bB}$ & 0,6 & \\
\hline & \multicolumn{4}{|c|}{ CMS (kg de matéria seca por100 kg de peso vivo por dia) } \\
\hline Águas & $1,81 \mathrm{aA}$ & $2,10 \mathrm{aA}$ & 0,12 & 0,0168 \\
\hline Seca & $1,87 \mathrm{aA}$ & $1,56 \mathrm{aB}$ & 0,12 & \\
\hline
\end{tabular}

${ }^{(1)}$ Médias seguidas de letras iguais, maiúsculas nas colunas e minúsculas nas linhas, não diferem entre si, pelo teste Tukey, a 5\% de probabilidade.
2007; Carvalho et al., 2008; Difante et al., 2009). Neste contexto, a cultivar Tupi apresenta estrutura de dossel mais favorável ao pastejo pelos animais, durante o período das águas.

Independentemente da cultivar, observaramse maiores PF, PC e RFNF e menor PM durante o período das águas (Tabela 1). O acréscimo em PM e a consequente alteração em RFNF, durante o período seco, estão associados à senescência natural da planta forrageira, ao manejo adotado e ao deficit hídrico (Figura 2). Forrageiras do gênero Urochloa sob lotação continua têm apresentado elevado acúmulo de material morto (Flores et al., 2008; Carloto et al., 2011; Nantes et al., 2013).

Quanto às variáveis associadas ao valor nutritivo, não houve interação entre cultivares e período do ano, com exceção da digestibilidade in vitro da matéria orgânica (DIVMO). Além disso, não houve diferença entre as cultivares quanto ao conteúdo de proteína bruta (PB), fibra em detergente neutro (FDN) e lignina em detergente ácido (LDA). Também, não se observaram diferenças entre períodos do ano, quanto aos teores de FDN, que apresentou média \pm erro-padrão de $74,7 \pm 0,17 \%$. No entanto, os períodos do ano tiveram efeito sobre os teores de PB e LDA (Tabela 2). Os teores de PB foram superiores no período das águas. Resultado semelhante foi observado por Pereira et al. (1992), para a Comum. Contudo, esses teores ficaram abaixo do adequado [7\%, de acordo com (Minson, 1990)], em ambos os períodos avaliados. Numa tentativa de agrupar as espécies do gênero Urochloa, quanto ao valor nutritivo, Lascano \& Euclides (1996) realizaram uma meta-análise em trabalhos publicados e as classificaram em dois grupos distintos de qualidade: 1, U. brizantha, $U$. decumbens e U. Ruziziensis; e 2, as cultivares de $U$. humidicola. Os autores relataram que a separação desses grupos esteve relacionada, principalmente, aos teores de PB.

No período das águas, observou-se menor teor de lignina em detergente ácido (LDA) e maiores teores de PB e DIVMO na forragem (Tabela 2). Esse resultado foi consequência, provavelmente, da maior TAF (Tabela 1) neste período, que teria resultado na maior proporção de plantas novas no pasto.

Independentemente da cultivar, a DIVMO foi maior no período das águas (Tabela 1). As cultivares não diferiram quanto a essa variável, nas águas; no entanto, 
a Tupi apresentou maior DIVMO do que a Comum, no período seco.

Moore et al. (1999), baseados na análise do valor nutritivo de 126 forrageiras, relataram que, quando a relação entre nutrientes digestíveis totais (que pode ser considerada equivalente a DIVMO) e PB for maior que sete, há déficit de nitrogênio em relação à energia disponível. Neste trabalho, independentemente das cultivares e da época do ano, esta relação foi de, aproximadamente, nove, o que indicou déficit de nitrogênio na forragem, durante todo o período experimental.

Observou-se interação entre os efeitos de gramínea e de estação do ano, quanto ao consumo de matéria seca (CMS). Contudo, independentemente do período avaliado, as cultivares as cultivares não diferiram quanto a essa variável (Tabela 1). Os animais em pasto de 'BRS Tupi' apresentaram CMS semelhantes, entre os períodos. No entanto, com a cultivar Comum, o CMS foi maior no período das águas. Pereira et al. (2009) também observaram maior CMS durante o período das águas para essa cultivar. Os baixos CMS observados nas duas espécies, e nos dois períodos, podem ser explicados pelos baixos teores de PB nas forrageiras (Tabela 2). Teores de PB na dieta abaixo de $6 \%$ reduzem a atividade dos microrganismos do rúmen, o que resulta em decréscimo nas taxas de digestão e de passagem do alimento, bem como no consumo voluntário pelos animais Minson (1990). Ressalta-se que os valores CMS obtidos para as duas cultivares, durante o período das águas, foi bem inferior ao observado por Pereira et al. (2009) para com a cultivar Comum.

A taxa de lotação (TL) sofreu influência da interação entre cultivares e estações do ano. Durante o período das águas, a 'BRS Tupi' suportou uma maior TL do que a 'Comum'; já no período seco, em razão de erros no manejo, a TL foi semelhante entre as cultivares (Tabela 3 ). Independentemente da cultivar, a TL foi maior no período das águas. As variações

Tabela 2. Média \pm erro-padrão dos teores de proteína bruta (PB) e de lignina em detergente ácido (LDA) de cultivares de Brachiaria humidicola em diferentes períodos do ano.

\begin{tabular}{lccc}
\hline Variável & Águas & Seca & p do período \\
\hline Proteína bruta (\%) & $6,0 \pm 0,08$ & $5,1 \pm 0,10$ & 0,0001 \\
LDA (\%) & $3,6 \pm 0,04$ & $4,2 \pm 0,05$ & 0,0001 \\
\hline
\end{tabular}

nas TL seguiram o mesmo padrão de variação da TAF (Tabela 1), de forma que, era necessário maior número de animais para manter a altura-meta, quando a TAF era maior. Decréscimo em TL durante o período seco também foi observado em $U$. brizantha, nas cultivares Xaraés (Carloto et al., 2011) e Marandu (Paula et al., 2012).

Quanto ao ganho médio diário (GMD), não houve interação entre os efeitos de cultivar e estação do ano, nem diferenças entre cultivares. No entanto, o GMD dos animais foi maior no período das águas (Tabela 3). Os valores de GMD, obtidos neste trabalho, foram muito inferiores aos observados por Pereira et al. (2009), em pastos da cultivar Comum, manejados com 2, 3 e 4 animais por hectare.

De acordo com o National Research Council (2000), as cultivares forneceram energia (Tabela 1) suficiente para o ganho de $450 \mathrm{~g}$ por dia, durante o período das águas; entretanto, o teor de proteína foi insuficiente (Tabela 2), já que, para este ganho, os teores de PB deveriam ser de aproximadamente 9\%. No período seco, observou-se perda de peso com as duas cultivares (Tabela 3). Neste caso, o resultado pode ser atribuído tanto à deficiência de proteína - que reduziu o CMS -, como à energia (Tabelas 1 e 2). Para a manutenção dos animais, seria necessária forragem com $7,9 \%$ de $\mathrm{PB}$ e $50 \%$ de DIVMO, e consumo de $2,2 \mathrm{~kg}$ de MS $100 \mathrm{~kg}^{-1}$ de PV. Moore et al. (1999) relatam que o baixo consumo de proteína bruta está diretamente ligado a baixo desempenho de animais em pastejo.

O ganho de peso vivo por área (GPVA) foi maior com a 'BRS Tupi'(192 $\pm 15 \mathrm{~kg} \mathrm{ha}^{-1}$ por ano) do que com a 'Comum' (126 $\pm 15 \mathrm{~kg} \mathrm{ha}^{-1}$ por ano). Essa diferença pode ser explicada pela maior TAF, observada na 'BRS Tupi', durante o período das águas (Tabela 1), que resultou em maior TL (Tabela 3) e, consequentemente, em maior GPVA.

Tabela 3. Médias de taxa de lotação e ganho médio diário (GMD), em pastos de cultivares de Brachiaria humidicola, em diferentes períodos do ano.

\begin{tabular}{lcccc}
\hline Cultivar & Águas & Seca & \multicolumn{2}{c}{ Erro-padrão p interação } \\
\hline & \multicolumn{5}{c}{ Taxa de lotação (UA ha $\left.{ }^{-1}\right)$} \\
'BRS Tupi' & $2,8 \mathrm{aA}$ & $1,2 \mathrm{bA}$ & 0,14 & 0,0092 \\
'Comum' & $2,0 \mathrm{aB}$ & $1,2 \mathrm{bA}$ & 0,14 & \\
\hline GMD (g por animal por dia) & 220 & -117 & 30 & \multicolumn{1}{c}{ ns } \\
\hline
\end{tabular}

${ }^{(1)}$ Médias seguidas de letras iguais, maiúsculas nas colunas e minúsculas nas linhas, não diferem entre si, pelo teste Tukey, a $5 \%$ de probabilidade. ${ }^{\text {ns Não }}$ significativo. UA, unidade animal $450 \mathrm{~kg}$.

Pesq. agropec. bras., Brasília, v.48, n.10, p.1402-1409, out. 2013 DOI: 10.1590/S0100-204X2013001000012 


\section{Conclusões}

1. A proteína bruta é o principal fator limitante do consumo de matéria seca e, consequentemente, do ganho de peso de animais em pastos de Urochloa humidicola.

2. A cultivar BRS Tupi possibilita maior ganho de peso vivo por área e, portanto, constitui uma boa alternativa para a diversificação de pastagens em solos de baixa fertilidade e sujeitos ao alagamento temporário.

\section{Agradecimentos}

À Fundação de Apoio ao Desenvolvimento do Ensino, Ciência e Tecnologia do Estado de Mato Grosso do Sul e ao Conselho Nacional de Desenvolvimento Científico e Tecnológico (CNPq), por apoio financeiro e concessão de bolsas.

\section{Referências}

CARLOTO, M.N.; EUCLIDES, V.P.B.; MONTAGNER, D.B.; LEMPP, B.; DIFANTE, G. dos S.; PAULA, C.C.L. de. Desempenho animal e características de pasto de capim-xaraés sob diferentes intensidades de pastejo, durante o período das águas. Pesquisa Agropecuária Brasileira, v.46, p.94-104, 2011. DOI: 10.1590/ S0100-204X2011000100013.

CARVALHO, P.C. de F.; GONDA, H.L.; WADE, M.H.; MEZZALIRA, J.C.; AMARAL, M.F. do; GONÇALVES, E.N.; SANTOS, D.T. dos; NADIN, L.; POLI, C.H.E.C. Características estruturais do pasto e o consumo de forragem: o quê pastar, quanto pastar e como se mover para encontrar o pasto. In: SIMPÓSIO SOBRE MANEJO ESTRATÉGICO DA PASTAGEM, 4.; SIMPÓSIO INTERNACIONAL SOBRE PRODUÇÃO ANIMAL EM PASTEJO, 2., 2008, Viçosa. Anais. Viçosa: Ed. da UFV, 2008. p.101-130.

COOK, B.G.; PENGELLY, B.C.; BROWN, S.D.; DONNELLY, J.L.; EAGLES, D.A.; FRANCO, M.A.; HANSON, J.; MULLEN, B.F.; PARTRIDGE, I.J.; PETERS, M.; SCHULTZE-KRAFT, R. Tropical forages: an interactive selection tool. Brisbane: CSIRO, 2005.

DIFANTE, G. dos S.; EUCLIDES, V.P.B.; NASCIMENTO JUNIOR, D. do; DA SILVA, S.C.; TORRES JUNIOR, R.A. de A.; SARMENTO, D.O. de L. Ingestive behaviour, herbage intake and grazing efficiency of beef cattle steers on Tanzania guineagrass subjected to rotational stocking managements. Revista Brasileira de Zootecnia, v.38, p.1001-1008, 2009. DOI: 10.1590/ S1516-35982009000600005.

FLORES, R.S.; EUCLIDES, V.P.B.;ABRÃO, M.P.C.; GALBEIRO, S.; DIFANTE, G. dos S.; BARBOSA, R.A. Desempenho animal, produção de forragem e características estruturais dos capins Marandu e Xaraés submetidos a intensidades de pastejo. Revista Brasileira de Zootecnia, v.37, p.1355-1365, 2008. DOI: 10.1590/ S1516-35982008000800004.
LASCANO, C.E.; EUCLIDES, V.P.B. Nutritional quality and animal production of Brachiaria pastures. In: MILES, J.W.; MAASS, B.L.; VALLE, C.B. do (Ed.). Brachiaria: biology, agronomy, and improvement. Cali: CIAT; Campo Grande: Embrapa-CNPGC, 1996. p.106-123. (CIAT. Publication, 259).

MINSON, D.J. Forage in ruminant nutrition. San Diego: Academic Press, 1990. 483p.

MOORE, J.E.; BRANT, M.H.; KUNKLE, W.E.; HOPKINS, D.I. Effects of supplementation on voluntary forage intake, diet digestibility, and animal performance. Journal of Animal Science, v.77, p.122-135, 1999. Supplement 2.

MOTT, G.O.; MOORE, J.E. Forage evaluation techniques in perspective. In: NATIONAL CONFERENCE ON FORAGE EVALUATIONAND UTILIZATION, 1970, Lincoln. Proceedings. Lincoln: Nebraska Center of Continuing Education, 1970. 10p.

NANTES, N.N.; EUCLIDES, V.P.B.; MONTAGNER, D.B.; LEMPP, B.; BARBOSA, R.A.; GOIS, P.O. de. Desempenho animal e características de pastos de capim-piatã submetidos a diferentes intensidades de pastejo. Pesquisa Agropecuária Brasileira, v.48, p.114-121, 2013. DOI: 10.1590/S0100-204X2013000100015.

NATIONAL RESEARCH COUNCIL. Nutrient requirements of beef cattle. $7^{\text {th }}$ ed. Washington: NRC, 2000. 244p.

PALHANO, A.L.; CARVALHO, P.C. de F.; DITTRICH, J.R.; MORAES, A. de; SILVA, S.C. da; MONTEIRO, A.L.G. Características do processo de ingestão de forragem por novilhas Holandesas em pastagem de capim-mombaça. Revista Brasileira de Zootecnia, v.36, p.1014-1021, 2007. DOI: 10.1590/ S1516-35982007000500005.

PAULA, C.C.L.; EUCLIDES, V.P.B.; MONTAGNER, D.B.; LEMPP, B.; DIFANTE, G.S.; CARLOTO, M.N. Estrutura do dossel, consumo e desempenho animal em pastos de capim-marandu sob lotação contínua. Arquivo Brasileiro de Medicina Veterinária e Zootecnia, v.64, p.169-176, 2012. DOI: 10.1590/S0102-09352012000100024.

PEDREIRA, B.C. e; PEDREIRA, C.G.S.; SILVA, S.C. da. Estrutura do dossel e acúmulo de forragem de Brachiaria brizantha cultivar Xaraés em resposta a estratégias de pastejo. Pesquisa Agropecuária Brasileira, v.42 p.281-287, 2007. DOI: 10.1590/ S0100-204X2007000200018.

PEREIRA, J.M.; NASCIMENTO JUNIOR, D. do; SANTANA, J.R. de; CANTARUTTI, R.B.; LEAO, M.I. Teor de proteína bruta e digestibilidade in vitro da matéria seca da forragem disponível e da dieta selecionada por bovinos em pastagem de Brachiaria humidicola (Rendle) Schweickt, em monocultivo ou consorciadas com leguminosas, submetida a diferentes taxas de lotação. Revista Brasileira Zootecnia, v.21, p.104-117, 1992.

PEREIRA, J.M.; TARRE, R.M.; MACEDO, R.; REZENDE, C. de P.; ALVES, B.J.R.; URQUIAGA, S.; BODDEY, R.M. Productivity of Brachiaria humidicola pastures in the Atlantic forest region of Brazil as affected by stocking rate and the presence of a forage legume. Nutrient Cycling in Agroecosystems, v.83, p.179-196, 2009. DOI: 10.1007/S10705-008-9206-Y.

PETERSEN, R.G.; LUCAS JUNIOR, H.L. Computing methods for evaluation of pastures by means of animal response. Agronomy 
Journal, v.60, p.682-687, 1968. DOI: 10.2134/agronj1968.00021 $962006000060031 x$.

PITTROFF, W.; SOCA, P. Physiology and models of feeding behaviour and intake regulation in ruminants. In: BELS, V.L. (Ed.). Feeding in domestic vertebrates: from structure to behaviour. Oxford: CAB, 2006. p.278-302. DOI: 10.1079/9781845930639.0278.

SANTOS, H.G. dos; JACOMINE, P.K.T.; ANJOS, L.H.C. dos; OLIVEIRA, V.A. de; OLIVEIRA, J.B. de; COELHO, M.R.; LUMBRERAS, J.F.; CUNHA, T.J.F. (Ed.). Sistema brasileiro de classificação de solos. 2.ed. Rio de Janeiro: Embrapa Solos, 2006. $306 \mathrm{p}$.

TRINDADE, J.K. da; DA SILVA, S.C.; SOUZA JÚNIOR, S.J. de; GIACOMINI, A.A.; ZEFERINO, C.V.; GUARDA, V. Del A.; CARVALHO, P.C. de F. Composição morfológica da forragem consumida por bovinos de corte durante o rebaixamento do capim-marandu submetido a estratégias de pastejo rotativo. Pesquisa Agropecuária Brasileira, v.42, p.883-890, 2007. DOI: 10.1590/S0100-204X2007000600016.
UNIPASTO. Associação para o Fomento à Pesquisa de Melhoramento de Forrageiras. Brachiaria humidicola: BRS Tupi. Disponível em: <http://www.unipasto.com.br/produtos/brs-tupi. pdf>. Acessado em: 4 dez. 2013.

VALADARES FILHO, S.C.; PAULINO, P.V.R.; SAINZ, R.D. Desafios metodológicos para determinação das exigências nutricionais de bovinos de corte no Brasil. In: REUNIÃO ANUAL DA SOCIEDADE BRASILEIRA DE ZOOTECNIA, 42., 2005, Goiânia. Anais. Goiânia: Sociedade Brasileira de Zootecnia, 2005. p.261-287.

VALLE, C.B.; MACEDO, M.C.M.; EUCLIDES, V.P.B.; JANK, L.; RESENDE, R.M.S. Gênero Brachiaria. In: FONSECA, D.M. da; MARTUSCELLO, J.A. (Ed.). Plantas forrageiras. Viçosa: Ed. da UFV, 2010. p.30-77.

WILLIANS, C.H.; DAVID, D.J.; IISMAA, O. The determination of chromic oxide in feces samples by atomic absorption spectrophotometry. The Journal of Agricultural Science, v.59, p.381-385, 1962. DOI: 10.1017/S002185960001546X.

Recebido em 9 de agosto de 2013 e aprovado em 30 de setembro de 2013

Pesq. agropec. bras., Brasília, v.48, n.10, p.1402-1409, out. 2013 DOI: 10.1590/S0100-204X2013001000012 